Check for updates

Cite this: RSC Adv., 2021, 11, 20063

\title{
Determination of folic acid by capillary zone electrophoresis with indirect chemiluminescence detection $\uparrow$
}

\author{
Tangjuan Zhao, Huaping Lin, Nan Li, Hongmei Shi, Weijun Kang (iD \\ and Xiangdong $\mathrm{Xu}$ (D) *
}

A capillary electrophoresis method with on-line inhibited chemiluminescence $(C L)$ detection was first used to determine folic acid (FA). This method was established based on the quenching effect of $F A$ on the $\mathrm{CL}$ reaction of luminol with a $\mathrm{Ag}(\mathrm{III})$ complex in alkaline medium. The separation was conducted with a $20.0 \mathrm{mM}$ sodium borate buffer containing $1.0 \mathrm{mmol} \mathrm{L}^{-1}$ luminol. Under optimized conditions, FA was baseline separated and detected in less than $10 \mathrm{~min}$. The limit of detection of FA was $1.3 \mathrm{mg} \mathrm{L}^{-1}$, with a linear range of $5.0-150.0 \mathrm{mg} \mathrm{L}^{-1}(r=0.9953)$. The RSD value was $2.8 \%$ for intra-day precision and $5.4 \%$ inter-day precision. The recoveries of the standard addition of tablets and human urine ranged from $90.3 \%$ to $107.5 \%$ and from 82.0 to $105.7 \%$, respectively. The proposed method was successfully applied to determine FA contents in commercial pharmaceutical tablets and human urine samples. Results suggested that this method was simple and robust.

Received 30th March 2021 Accepted 19th May 2021

DOI: $10.1039 / \mathrm{d} 1 \mathrm{ra02502 \textrm {c }}$

rsc.li/rsc-advances detection is a simple analytical instrument for FIA, HPLC, and CE because the absence of a light source in CL detectors significantly reduces noise and eliminates Rayleigh and Raman scattering. The low limits of detections (LODs) and wide linear range of CL detector are comparable to laser-induced fluorescence. Still, the cost is much lower, rendering CE-CL an alternative to sensitive detection.

In our previous study, we demonstrated for the first time that the oxidation of luminol by the $\mathrm{Ag}$ (III) complex could generate CL in alkaline media. ${ }^{24} \mathrm{CE}$ coupled with an Ag(III) complexluminol system has been successfully used to determine EP, NE, and DA in urine samples from healthy individuals and pheochromocytoma patients. ${ }^{25}$ The use of the Ag(III) complex as an oxidant in CE-CL has not yet been extensively explored despite its essential advantages. On the one hand, the complex is a rather powerful oxidizing agent (oxidation potential $=1.74 \mathrm{~V}$ ) with a fast reaction rate; thus, the CE-CL configuration is simple and provides sharp peaks. On the other hand, current loss (caused by air bubbles formed in the $\mathrm{H}_{2} \mathrm{O}_{2}$-luminol reaction) is not a problem. The formation of bubbles could cause

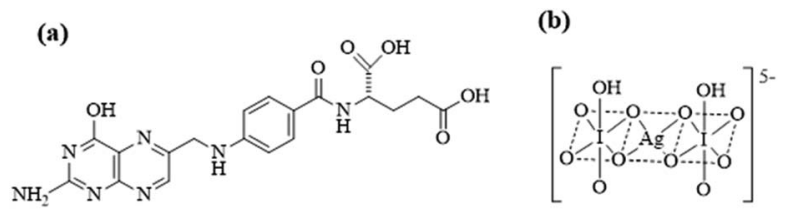

Fig. 1 Chemical structure of (a) folic acid and (b) Ag(III) complex.
Hebei Key Laboratory of Environment and Human Health, School of Public Health, Hebei Medical University, Shijiazhuang, 050017, PR China. E-mail: xuxd@hebmu. edu.cn

$\dagger$ Electronic supplementary information (ESI) available. See DOI: $10.1039 / \mathrm{d} 1 \mathrm{ra} 02502 \mathrm{c}$ 
unstable electrophoretic currents resulting in an unstable CL electropherogram baseline, thereby reducing separation efficiency and increasing noise.

The reaction of luminol with $\mathrm{Ag}$ (III) complex produces an intense CL emission, so that the analytes can have two effects: enhancement or inhibition of CL emission. The derivatization of non-CL analytes prior to detection is generally required because few chemicals show natural CL characteristics. However, derivatization processes are often tedious and timeconsuming. In addition, the quantitative labeling of the lowconcentration analyte is also difficult. Alternatively, if a nonCL analyte interfere with or suppress a CL reaction, the analyte can be indirectly detected as an inverted peak where the CL intensity decreases from a normally high background. We call this process indirect CL detection. Some CE-indirect CL methods have been developed for the determination of amino acids, catecholamines, polyphenols, 5-hydroxyindoleacetic acids, and 5-hydroxytryptamine. ${ }^{26-29}$

In the present work, a rapid, simple, and sensitive CEindirect CL detection was used to determine FA in commercial pharmaceutical tablets and human urine based on the quenching effect of FA on the CL reaction of luminol with $\mathrm{Ag}$ (III) complex in alkaline medium. The conditions for the CL reaction and electrophoresis were investigated in detail using an $\mathrm{Ag}$ (III) complex-luminol system. The determination of FA concentration in commercial pharmaceutical tablets and human urine samples was investigated as an application example for the proposed CE-CL system.

\section{Experimental}

\subsection{Chemicals and reagents}

All reagents used in the experiment were of analytical grade unless otherwise mentioned. FA (Fig. 1a) was obtained from the Chinese Food and Drug Inspection Institute (Beijing, China). $\mathrm{AgNO}_{3}, \mathrm{KIO}_{4}, \mathrm{~K}_{2} \mathrm{~S}_{2} \mathrm{O}_{8}, \mathrm{KOH}$, hydrochloric acid, sodium metabisulphite, sodium borate, and EDTA were obtained from Beijing Chemical Reagent Company (Beijing, China). Luminol was purchased from TCI Shanghai (Shanghai, China). Ag(III) stock solution was prepared in accordance with a previously described method. ${ }^{19}$ Experimental water was ultrapure water.

\subsection{Preparation of standard solutions and CL solutions}

Stock solutions $\left(1.0 \mathrm{mg} \mathrm{mL}^{-1}\right)$ of FA were prepared by dissolving $10 \mathrm{mg}$ of FA in $10 \mathrm{~mL}$ of water. A $20 \mathrm{mM}$ luminol solution was prepared by dissolving $0.8860 \mathrm{~g}$ of luminol in $7.00 \mathrm{~mL}$ of $1 \mathrm{M}$ $\mathrm{NaOH}$ followed by dilution with water to $250 \mathrm{~mL}$. A $0.1 \mathrm{M}$ sodium borate stock solution was prepared by dissolving $3.814 \mathrm{~g}$ of $\mathrm{Na}_{2} \mathrm{~B}_{4} \mathrm{O}_{7} \cdot 10 \mathrm{H}_{2} \mathrm{O}$ in $100 \mathrm{~mL}$ of water. Bis(hydrogenperiodato)argentate(III) complex anion $\left[\mathrm{Ag}\left(\mathrm{HIO}_{6}\right)_{2}\right]^{5-}$ was synthesized according to a previously described procedure. ${ }^{30}$ Chemical structure of $\mathrm{Ag}$ (III) complex was shown in Fig. $1 \mathrm{~b}$. The electronic spectrum of the $\mathrm{Ag}$ (III) complex in an aqueous solution showed two absorption bands at 362 and $253 \mathrm{~nm}$, in excellent agreement with previously reported results. ${ }^{31}$ Stock solutions of the Ag(III) complex were prepared fresh daily from the solid-state compound, and concentration was determined spectrophotometrically at $362 \mathrm{~nm}$ using molar absorptivity $\varepsilon=1.26 \times 10^{4} \mathrm{M}^{-1} \mathrm{~cm}^{-1} \cdot{ }^{30}$ Working solutions were freshly prepared by diluting standard stock solutions with ultrapure water. All solutions were refrigerated at $4{ }^{\circ} \mathrm{C}$.

\subsection{Laboratory-built CE-CL system}

All experiments were performed with a laboratory-built CE-CL system. The device consisted of a high-voltage source that supplied up to $30 \mathrm{kV}$ (Tianjin Dongwen High Voltage Power Supply Limited Company, Tianjin, China), two platinum electrodes (the anode or high-voltage electrode at the inlet, and the cathode or ground electrode at the outlet), a photomultiplier tube (Binsong, Beijing, China) that collected the CL emission, and a PEEK three-way connector with an inner diameter (i.d.) of $600 \mu \mathrm{m}$ (Keshi Scientific, Xiamen, China) that connected the separation, reagent, and reaction capillaries (Fig. 2). Uncoated fused silica capillaries $65 \mathrm{~cm} \times 50 \mu \mathrm{m}$ i.d. were used for the separation. The $6 \mathrm{~cm}$ end section of the capillary coated with polyimide was burned and moved. The separation capillary was etched with hydrofluoric acid for $40 \mathrm{~min}$ to $50 \mathrm{~min}$ and then inserted into a reaction capillary with a diameter of $530 \mu \mathrm{m}$. The separation capillary, reaction capillary, and reagent capillary were held by a three-way Plexiglass apparatus. The Ag(III) solution was delivered by gravity to the detection window by burning $5 \mathrm{~mm}$ of the polyimide of the reaction capillary and then placed before the photomultiplier tube (PMT). The luminol and Ag(III) complex were mixed in front of the PMT to produce CL, the CL signal was amplified in the PMT, and the photocurrent was recorded using data acquisition software (Qianpu Software Ltd., Shanghai, China). The entire CL detection system was prepared in an opaque box to avoid the effects of external light.

\subsection{Electrophoresis}

Before first use, the capillary was conditioned by flushing with $1 \mathrm{M} \mathrm{NaOH}$ for $30 \mathrm{~min}$ followed by water for $20 \mathrm{~min}$. At the beginning of each day, the capillary was sequentially rinsed using a syringe containing $0.1 \mathrm{M} \mathrm{NaOH}, 0.1 \mathrm{M} \mathrm{HCl}$, and doubly distilled water; each rinse lasted $10 \mathrm{~min}$. The separation

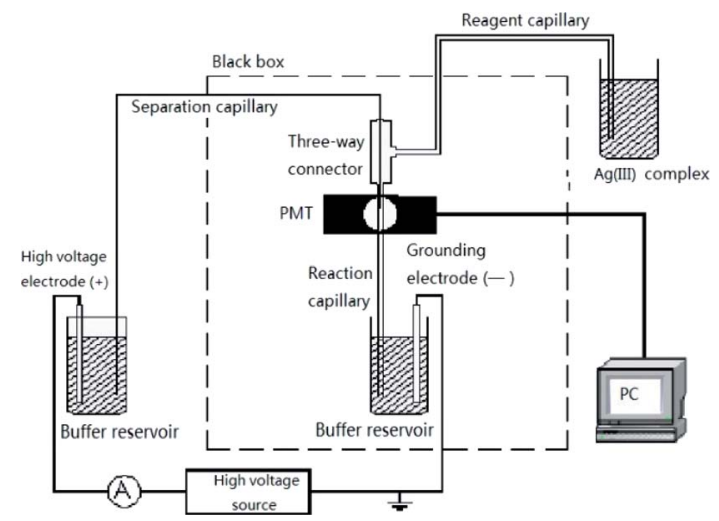

Fig. 2 High-performance capillary electrophoresis chemiluminescence apparatus. 
capillary was then equilibrated with the migration buffer for $20 \mathrm{~min}$ in pressure mode. The reagent capillary was first filled with the $\mathrm{Ag}$ (III) complex solution using a syringe. During electrophoresis, the reservoir containing the Ag(III) complex solution was placed $20 \mathrm{~cm}$ above the reaction capillary outlet to continuously deliver the Ag(III) complex solution by gravity. Luminol was added to the running buffer and introduced into the separation capillary by electroosmotic flow. The sample solutions were introduced at the cathode by gravity for $10 \mathrm{~s}$ from a height of $40 \mathrm{~cm}$. After separation by capillary electrophoresis, the analyte zones were determined by indirect CL of luminol$\mathrm{Ag}$ (III) complex. FA was quantified by measuring the net $\mathrm{CL}$ intensity $\Delta I=I_{0}-I_{\mathrm{i}}$, where $I_{0}$ was the CL background intensity of the luminol-Ag(III) complex reaction, and $I_{\mathrm{i}}$ was the $\mathrm{CL}$ intensity of the analyte.

\subsection{Sample preparation}

Commercial pharmaceutical FA tablets (mark content $0.4 \mathrm{mg}$ per each piece) were purchased from a pharmacy. Ten tablets were weighed and ground into powder. The powder was dissolved in $5 \mathrm{~mL}$ of $0.01 \mathrm{~mol} \mathrm{~L}^{-1} \mathrm{NaOH}$, and the volume was adjusted to $10 \mathrm{~mL}$ by adding water. The solution was shaken for $30 \mathrm{~min}$ and filtered through a $0.22 \mu \mathrm{m}$ syringe filter before CE separation.

Fresh human urine samples were obtained from different volunteers. FA was extracted from the biological samples using an SCX cartridge (200 mg, $3 \mathrm{~mL}$, Simon, Germany). The cleanup process was as follows: (1) the SPE Cartridge was conditioned with $2.0 \mathrm{~mL}$ of methanol and $2.0 \mathrm{~mL}$ of water before use; (2) urine $(1.0 \mathrm{~mL})$ was slowly loaded into the conditioned cartridge; (3) the cartridge was then washed with $1 \mathrm{~mL}$ of $5 \%$ methanol; and (4) FA was eluted with $1 \mathrm{~mL}$ of a solution containing ammonia: methanol $(10: 90, \mathrm{v} / \mathrm{v})$. This extract was dried with nitrogen and dissolved in $1 \mathrm{~mL}$ of $0.005 \mathrm{~mol} \mathrm{~L}^{-1} \mathrm{NaOH}$.

Spiked samples were prepared by adding the specific volume of standard solutions of FA to the FA tablets samples and fresh human urine samples and then repeated the above procedures.

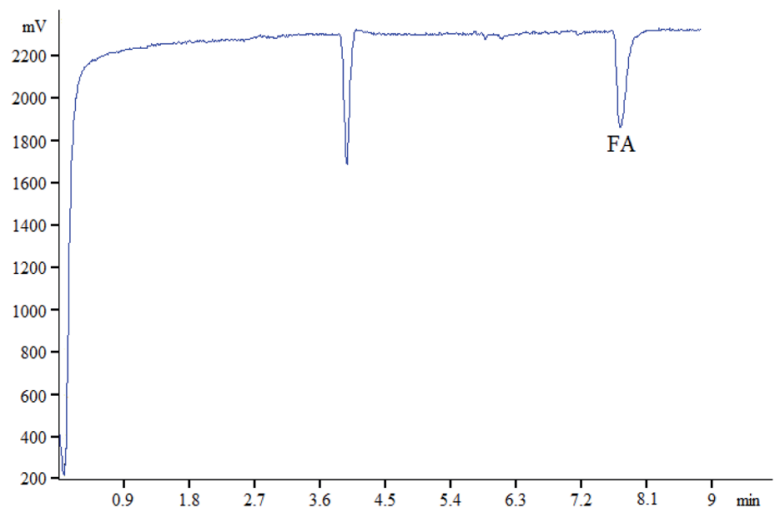

Fig. 3 Electrophergram of substance to be tested. (Condition: $65 \mathrm{~cm}$ $\times 50 \mu \mathrm{m}$ i.d. fused silica; applied voltage:18 kV; injection time:15 S; $C_{\mathrm{Ag}(\mathrm{III})}=5.0 \times 10^{-5} \mathrm{~mol} \mathrm{~L}^{-1}$ in $0.01 \mathrm{~mol} \mathrm{~L}^{-1} \mathrm{NaOH} ; C_{\text {luminol }}=2 \mathrm{mmol}$ $\mathrm{L}^{-1}$ in $5 \mathrm{mmol} \mathrm{L}^{-1}$ sodium tetraborate; FA: $100 \mathrm{mg} \mathrm{L}^{-1}$ ).

\section{Results and discussion}

\subsection{Effect of FA on CL intensity}

The Ag(III) complex-luminol system could generate a stable CL intensity in alkaline condition, while FA significantly inhibits the CL. In the experiment, $100 \mathrm{mg} \mathrm{L}^{-1}$ of FA was analyzed, and its CL signal was obtained within 10 min (Fig. 3).

\subsection{CL condition selection}

3.2.1. Effect of luminol on $\mathrm{CL}$ intensity. Under alkaline conditions, luminol was oxidized by an oxidant to generate excited luminescent intermediate. When it transitioned from the excited state to the ground state, blue light (i.e. CL) was generated at $425 \mathrm{~nm}$. Therefore, when the amount of the oxidant was sufficient, the concentration of luminol would affect the CL intensity. However, when the concentration of luminol was too high or the oxidant was consumed completely, the CL intensity tended to be stable.

The effects of the luminol concentration ranging from $1 \times$ $10^{-3} \mathrm{~mol} \mathrm{~L}^{-1}$ to $4 \times 10^{-3} \mathrm{~mol} \mathrm{~L}^{-1}$ were evaluated. The results were shown in Fig. 4. As the concentration of luminol increased, the CL intensity also increased; by contrast, the signal reached the maximum when the luminol concentration reached $2.5 \times$ $10^{-3} \mathrm{~mol} \mathrm{~L}^{-1}$. Therefore, the optimum luminol concentration was $2.5 \times 10^{-3} \mathrm{~mol} \mathrm{~L}^{-1}$.

3.2.2. Effect of $\mathbf{A g}$ (III) on $\mathbf{C L}$ intensity. In this experiment, $\mathrm{Ag}$ (III) was used as the oxidant of the CL system. On the one hand, too low concentration of the Ag(III) solution would cause the intensity of CL system to decrease, and the decrease of the baseline would reduce the inhibitory effect of the sample on CL. on the other hand, too high concentration of $\mathrm{Ag}$ (III) solution would form a darker color solution, which had a certain selfabsorption effect on CL system and would cause the decrease of the CL intensity.

The effect of $\mathrm{Ag}(\mathrm{III})$ concentration ranging from $1.0 \times$ $10^{-5} \mathrm{~mol} \mathrm{~L}^{-1}$ to $1.0 \times 10^{-4} \mathrm{~mol} \mathrm{~L}^{-1}$ on the CL intensity was investigated (Fig. 5). As the concentration of $\mathrm{Ag}$ (III) increased, the CL intensity initially increased and then decreased. The

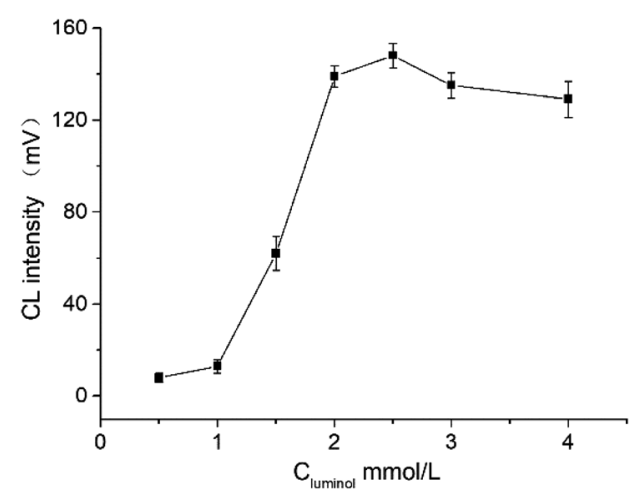

Fig. 4 Effect of the concentration of luminol on $\mathrm{CL}$ intensity. (Condition: $65 \mathrm{~cm} \times 50 \mu \mathrm{m}$ i.d. fused silica; applied voltage: $18 \mathrm{kV}$; injection time: $15 \mathrm{~S} ; \mathrm{C}_{\mathrm{Ag}(\mathrm{III})}=5.0 \times 10^{-5} \mathrm{~mol} \mathrm{~L}^{-1}$ in $0.03 \mathrm{~mol} \mathrm{~L}^{-1} \mathrm{NaOH}$; luminol in $5 \mathrm{mmol} \mathrm{L}^{-1}$ sodium tetraborate; FA: $100 \mathrm{mg} \mathrm{L}^{-1}$ ). 


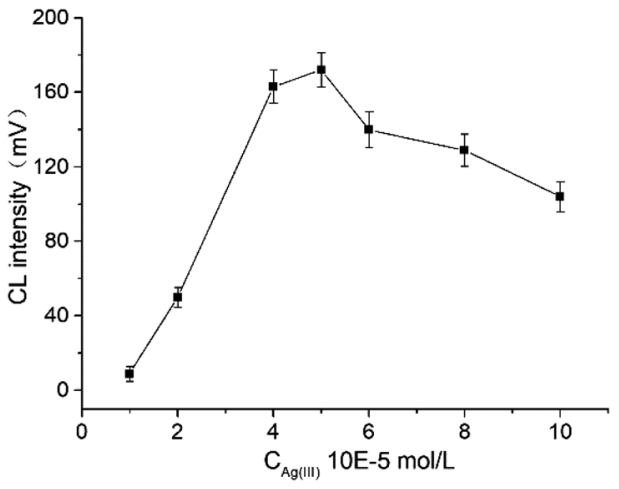

Fig. 5 Effect of the concentration of $\mathrm{Ag}(\mathrm{III})$ on $\mathrm{CL}$ intensity. (Condition: $65 \mathrm{~cm} \times 50 \mu \mathrm{m}$ i.d. fused silica; applied voltage: $18 \mathrm{kV}$; injection time: $15 \mathrm{~S}$; $\mathrm{Ag}(\mathrm{III})$ in $0.03 \mathrm{~mol} \mathrm{~L}^{-1} \mathrm{NaOH} ; \mathrm{C}_{\text {luminol }}=2 \mathrm{mmol} \mathrm{L}^{-1}$ in $5 \mathrm{mmol} \mathrm{L}^{-1}$ sodium tetraborate; $F A: 100 \mathrm{mg} \mathrm{L}^{-1}$ ).

maximum CL intensity was obtained when the concentration was $5.0 \times 10^{-5} \mathrm{~mol} \mathrm{~L}^{-1}$. Therefore, the optimum concentration of $\mathrm{Ag}$ (III) was $5.0 \times 10^{-5} \mathrm{~mol} \mathrm{~L}^{-1}$.

3.2.3. Effect of $\mathbf{N a O H}$ on $\mathrm{CL}$ intensity in $\mathrm{Ag}$ (III) solution. The reaction of $\mathrm{Ag}$ (III)-luminol CL system required suitable $\mathrm{pH}$ condition. The effect of $\mathrm{NaOH}$ concentration on the CL intensity was optimized within the range of $0.01 \mathrm{~mol} \mathrm{~L}^{-1}$ to $0.06 \mathrm{~mol} \mathrm{~L}^{-1}$ (Fig. 6). As the concentration of $\mathrm{NaOH}$ increased from $0.01 \mathrm{~mol} \mathrm{~L}^{-1}$ to $0.03 \mathrm{~mol} \mathrm{~L}^{-1}$, the CL intensity of FA increased. As the concentration of $\mathrm{NaOH}$ continuously increased, the signal decreased. Thus, the concentration of $0.03 \mathrm{~mol} \mathrm{~L}^{-1}$ $\mathrm{NaOH}$ was selected for the experiment.

\subsection{Separation condition selection}

3.3.1. Effect of borax on CL intensity. The ionic strength of the solution varied with the concentration of borax in the buffer. The appropriate concentration of borax could increase the CL intensity and improve the separation efficiency of the sample. When the concentration of borax was lower than $1 \times$ $10^{-3} \mathrm{~mol} \mathrm{~L}^{-1}$, the peak shape of FA was poor and tailing occurred. As the concentration of borax increased, the migration time of the target would gradually extend.

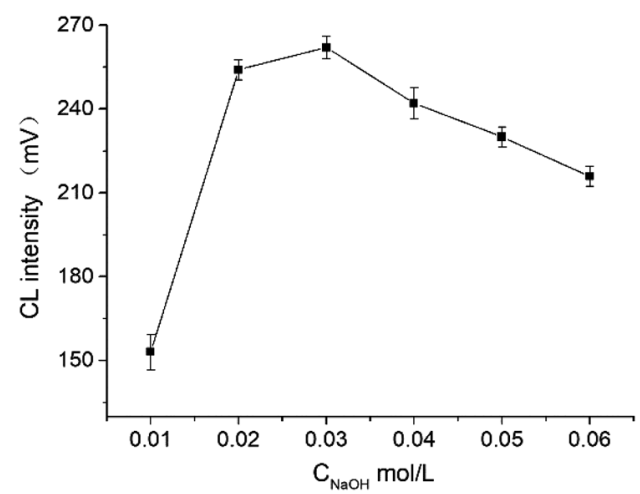

Fig. 6 Effect of the concentration of $\mathrm{NaOH}$ in $\mathrm{Ag}(\mathrm{III})$ solution (Condition: $65 \mathrm{~cm} \times 50 \mu \mathrm{m}$ i.d. fused silica; applied voltage: $13 \mathrm{kV}$; injection time: $15 \mathrm{~S} ; C_{\mathrm{Ag}(\mathrm{II})}=5 \times 10^{-5} \mathrm{~mol} \mathrm{~L}^{-1} ; C_{\text {luminol }}=2.5 \mathrm{mmol} \mathrm{L}^{-1}$ in $5 \mathrm{mmol} \mathrm{L}^{-1}$ sodium tetraborate; FA: $100 \mathrm{mg} \mathrm{L}^{-1}$ ).
In the study, the influence of borax concentration ranging from $1 \times 10^{-3} \mathrm{~mol} \mathrm{~L}^{-1}$ to $15 \times 10^{-3} \mathrm{~mol} \mathrm{~L}^{-1}$ on CL intensity was investigated. Results indicated that the CL intensity was enhanced as the borax concentration increased from $1 \times$ $10^{-3} \mathrm{~mol} \mathrm{~L}^{-1}$ to $5 \times 10^{-3} \mathrm{~mol} \mathrm{~L}^{-1}$. By contrast, the CL intensity decreased when the borax concentration exceeded $5 \times$ $10^{-3} \mathrm{~mol} \mathrm{~L}^{-1}$. Therefore, $5 \times 10^{-3} \mathrm{~mol} \mathrm{~L}^{-1}$ borax was selected for further experiments.

3.3.2. Effect of voltage on CL intensity. The voltage plays a critical role in CE procedure because it affects the separation efficiency, analysis speed, signal-to-noise ratio and CL intensity of the target. In order to obtained excellent separation efficiency, the voltage applied from $18 \mathrm{kV}$ to $26 \mathrm{kV}$ was investigated. The result showed that the lower voltage would bring a longer analysis time and a wider peak width. As the voltage increased, CL intensity initially increased and then decreased. The maximum CL intensity was obtained when the voltage was 22 $\mathrm{kV}$. Therefore, $22 \mathrm{kV}$ was selected. In principle, the separation efficiency of CE is proportional to the applied voltage. However, the applied voltage is limited by Joule heating because it triggers luminol electrolysis at high potentials. We noticed that both the noise and signals increased with voltages of $13-26 \mathrm{kV}$. The best signal-to-noise ratio was observed at the $22 \mathrm{kV}$ separation voltage. Therefore, $22 \mathrm{kV}$ was chosen for subsequent work. We replaced the running buffer solution in two electrophoresis reservoirs after each separation to retain the stability of the chemiluminescence baseline because luminol was easily electrooxidized by CE's high voltage.

\subsection{Optimization of injection time}

Injection time is an important factor in separation process. The effect of injection time on the CL intensity was investigated from 8-25 s. The signal intensity of the analyte gradually increased with the increase of injection time up to $20 \mathrm{~s}$. With the extension of injection time, the signal intensity of analyte and the separation efficiency had no improvement, and the peak width would broaden. According to the experimental results, the optimum injection time was determined as $20 \mathrm{~s}$.

\subsection{Linearity, LOD, and precision}

Under the above conditions, the concentration of FA showed a good linear relationship between $5 \mathrm{mg} \mathrm{L}^{-1}$ and $150 \mathrm{mg} \mathrm{L}^{-1}$. The linear regression equation was $y=3.5051 x+9.916$ with a correlation coefficient $(r)$ of 0.9953 , where $y$ was the peak area and $x$ was concentration. LOD was determined as the concentration at the signal-to-noise ratios $(\mathrm{S} / \mathrm{N})$ of 3 times was $1.3 \mathrm{mg} \mathrm{L} \mathrm{L}^{-1}$. The precision of the method was investigated by intra-day and inter-day relative standard deviations (RSDs), which were evaluated via analyzing a standard solution of FA in eleven injections on the same day and three consecutive days, respectively. The RSD value was $2.8 \%$ for intra-day precision and $5.4 \%$ inter-day precision.

\subsection{Application in actual sample}

The established method was applied for the detection of FA in commercial pharmaceutical FA tablets purchased from a local 
Table 1 Comparison of results obtained using different methods

\begin{tabular}{llll}
\hline Times & $\begin{array}{l}\text { CE-CL }(\mathrm{mg} \\
\left.\mathrm{L}^{-1}\right)\end{array}$ & HPLC $\left(\mathrm{mg} \mathrm{L}^{-1}\right)$ & $p$-Value \\
\hline 1 & 39.96 & 40.33 & 0.851 \\
2 & 41.39 & 40.32 & \\
3 & 40.82 & 40.39 & \\
4 & 40.53 & 40.36 & \\
5 & 39.68 & 40.38 & \\
6 & 39.40 & 40.37 & \\
Average & 40.30 & 40.36 & \\
& &
\end{tabular}

pharmacy (Shijiazhuang, China) and human urine. Urine samples were collected from healthy volunteers from Hebei Medical University and from the First Hospital of Hebei Medical
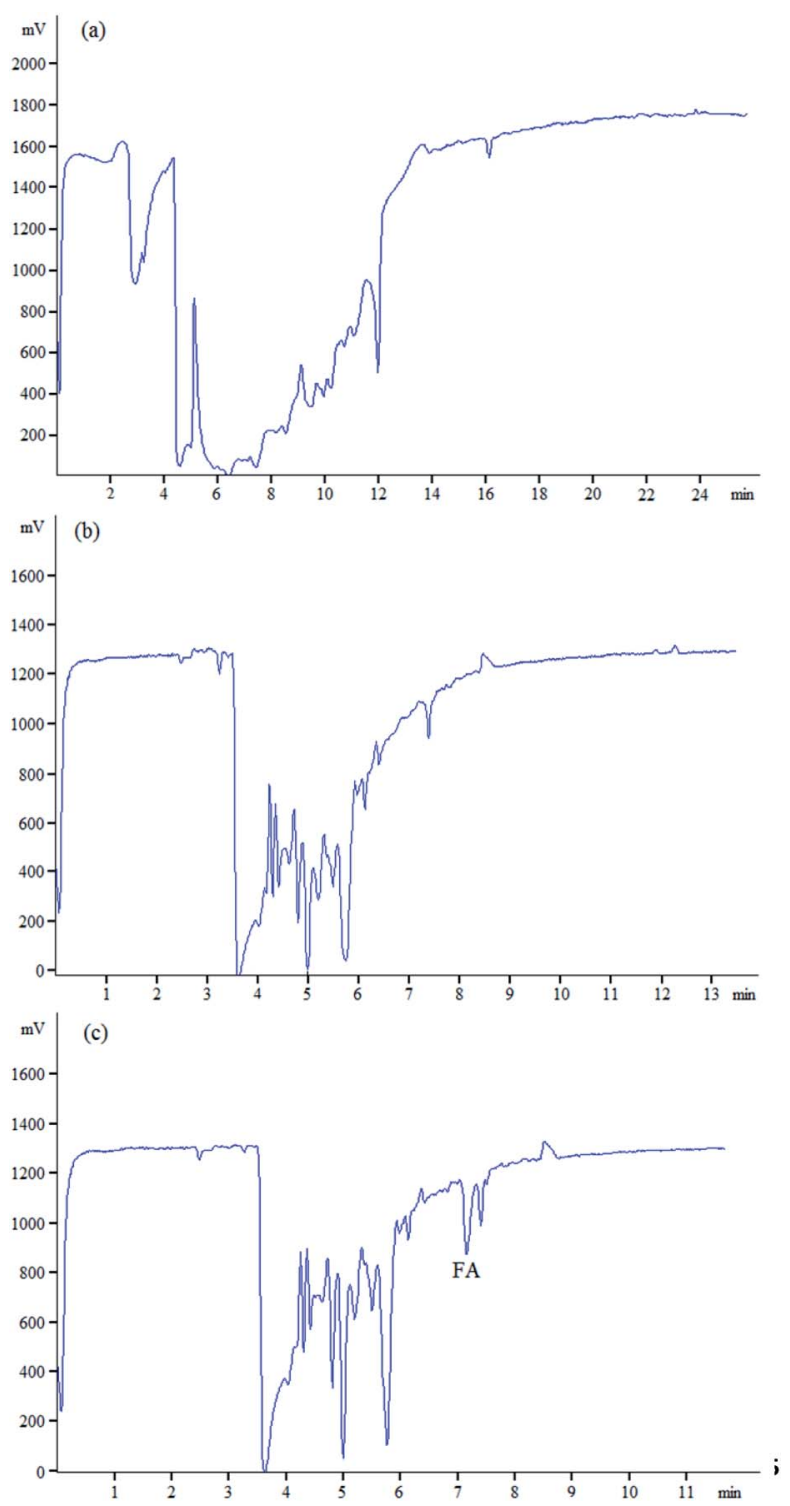

Fig. 7 Electropherograms obtained (a) from urine sample without SPE, (b) from urine sample, and (c) from the sample spiked with FA at $44 \mathrm{mg} \mathrm{L}^{-1}$ after SPE procedure.
University. All experiments were performed in accordance with relevant laws and institutional guidelines. Experiments were approved by the ethics committee at Hebei Medical University. Informed consents were obtained from human participants of this study.

FA tablets were analyzed in parallel six times, and the results were summarized in Table 1. The method was compared with the HPLC method in "Standard Methods of Chinese Pharmacopoeia" for the detection of FA. Then, $t$-test was performed based on the results of the two methods. No significant difference $(p>0.05)$ between the determination results of the two methods was found, indicating that the proposed CE-CL method was simple and reliable. Moreover, the proposed method required a small amount of sample and fewer reagents, which showed environmental friendliness.

The method was used to determine FA in human urine samples to verify the applicability of the method to detect FA in complex biological samples. In Fig. 7a, when urine samples were directly injected for determination without purification, a large number of interference peaks appeared around the retention time of $\mathrm{FA}$, which made it impossible to analyze FA accurately. So, the urine samples were purified through solidphase extraction because of the complex components of human urine (Fig. 7b and c). The matrix of human urine had an inhibitory effect on the CL intensity in the indirect detection, whereas the influence was not observed in the separation of standard solutions. Therefore, the correction of matrix inhibition was necessary. After the correction of matrix inhibition, Fig. 7b and c show the typical electropherograms of the blank human urine and spiked human urine. Fig. $7 \mathrm{~b}$ shows that no FA signal was found in blank human urine for the concentration was lower than the limit of detection. In Fig. 7c, no interference peaks were observed within the retention time window, which indicated the proposed method was accurate and reliable. The urine of fourteen pregnant women who took $400 \mu \mathrm{g}$ of FA daily for 21 consecutive days was analyzed using the established method. The concentration of FA in urine before FA supplementation and after FA supplementation are shown in Table 2. The results showed that after intaking FA continuously, the content of FA in pregnant women increased to varying degrees, except for sample 6. Pregnant women could gain FA from FA tablets.

To further evaluate the accuracy of the proposed method, recovery experiments were performed by analysis of the spiked samples at three concentration levels (low, medium, and high) in three replicates. As shown in Table 3, the spiked recoveries of the standard addition of tablets and human urine were in the range of $90.3-107.5 \%$, with RSD values varying from $1.2 \%$ to $5.2 \%$ and in the range of $82.0-105.7 \%$ with RSD values varying from $4.2 \%$ to $8.4 \%$, respectively. The developed method was compared with other detection methods reported for the determination of FA (Table S1 $\dagger$ ). It was indicating that the proposed method enables accurate and reliable analysis of FA in Tablets samples and complex biological samples. 
Table 2 The concentration of FA in urine samples

\begin{tabular}{|c|c|c|c|c|c|}
\hline Samples & Initial $\left(\mathrm{mg} \mathrm{L}^{-1}\right)$ & Spiked $\left(\mathrm{mg} \mathrm{L}^{-1}\right)$ & Found $\left(\mathrm{mg} \mathrm{L}^{-1}\right)$ & Recovery (\%) & RSD (\%) \\
\hline \multirow[t]{2}{*}{ FA tablets $(n=3)$} & 41.7 & 8 & 50.3 & 107.5 & 1.2 \\
\hline & 41.7 & 20 & 61.0 & 96.5 & 5.2 \\
\hline \multirow[t]{3}{*}{ Urine $(n=3)$} & n.d. ${ }^{a}$ & 44 & 46.53 & 105.7 & 4.2 \\
\hline & n.d. & 77 & 68.78 & 89.3 & 6.8 \\
\hline & n.d. & 110 & 90.18 & 82.0 & 8.4 \\
\hline
\end{tabular}

${ }^{a}$ n.d., not detected or lower than limits of detection.

Table 3 Recovery of the proposed method

\begin{tabular}{|c|c|c|c|c|c|}
\hline Sample & $\begin{array}{l}\text { Before intake } \\
\text { of FA }\left(F A, \mathrm{mg} \mathrm{L}^{-1}\right)\end{array}$ & $\begin{array}{l}\text { After intake } \\
\text { of FA }\left(\mathrm{FA}, \mathrm{mg} \mathrm{L}^{-1}\right)\end{array}$ & Sample & $\begin{array}{l}\text { Before intake } \\
\text { of FA }\left(\mathrm{FA}, \mathrm{mg} \mathrm{L}^{-1}\right)\end{array}$ & $\begin{array}{l}\text { After intake } \\
\text { of } \mathrm{FA}\left(\mathrm{FA}, \mathrm{mg} \mathrm{L}^{-1}\right)\end{array}$ \\
\hline 1 & 0.807 & 0.862 & 8 & 0.507 & 0.783 \\
\hline 3 & 0.926 & 1.070 & 10 & 0.682 & 0.955 \\
\hline 4 & 0.906 & 1.301 & 11 & 0.831 & 1.168 \\
\hline 5 & 0.706 & 1.158 & 12 & 1.046 & 1.141 \\
\hline
\end{tabular}

\section{Conclusion}

In this study, CE coupled with an $\mathrm{Ag}$ (III) complex-luminol system was established. The application of the CE-CL method for the analysis of FA in tablets and human urine shortened the analysis time and provided a satisfactory detection efficiency. Under the optimized conditions, satisfactory results, including good linearities, low LOD, high precision, and high spiked recoveries, were obtained, which exhibited the great promise of the CL method in actual sample analysis. Moreover, the established method also showed the advantages of economic and environmental friendliness. As a whole, the developed CE-CL method could be a reliable alternative for better application in FA determination from other complex biological samples.

\section{Conflicts of interest}

There are no conflicts to declare.

\section{Acknowledgements}

This work was financially supported by the Natural Science Foundation of China (No. 81402723), the Natural Science Foundation of Hebei Province (No. H2018206279, H2020206516, 19977719D), Specific Project for Winter Olympics Games (No. 19977719D). The Youth Foundation of Hebei Educational Committee (No. QN2020129), and the Young Science and Technological Innovation Talents Support and Cultivation Plan of Hebei Medical University (No. TJZR202004).

\section{References}

1 S. E. Vollset, R. Clarke, S. Lewington, M. Ebbing, J. Halsey, E. Lonn, J. Armitage, J. E. Manson, G. J. Hankey, J. D. Spence, P. Galan, K. H. Bønaa, R. Jamison, J. M. Gaziano, P. Guarino, J. A. Baron, R. F. A. Logan, E. L. Giovannucci, M. Heijer, P. M. Ueland, D. Bennett, R. Collins and R. Peto, Lancet, 2013, 381, 1029-1036.

2 V. Tarlaulikar and S. Arulkumaran, Obstet. Gynaecol. Reprod. Med., 2013, 23, 286-288.

3 S. J. Duthie, J. Inherit. Metab. Dis., 2011, 34(1), 101-109.

4 C. Y. Li, Q. Yang, X. Y. Wang, M. Arabi, H. L. Peng, J. H. Li, H. Xiong and L. X. Chen, Food Chem., 2020, 319, 126575.

5 Q. Yang, C. Y. Li, J. H. Li, X. Y. Wang, M. Arabi, H. P. Peng, H. Xiong and L. X. Chen, Nanoscale, 2020, 12(11), 6529-6536. 6 A. Heydari, M. R. Vardast and S. Yeganeh Zare, Urmia. Med. J., 2015, 25(12), 1102-1111.

7 E. M. Tornero, A. E. Mansilla and I. D. Merás, Microchem. J., 2017, 133, 333-345.

8 A. Mahato, S. Vyas and N. S. Chatterjee, J. AOAC Int., 2020, 103(1), 73-77.

9 R. Amidžić, J. S. Brborić, O. A. Čudina and S. Vladimirov, J. Serb. Chem. Soc., 2005, 70(10), 1229-1235.

10 Z. Szakács and B. Noszál, Electrophoresis, 2006, 27(17), 33993409.

11 S. L. Zhao, H. Y. Yuan, C. Xie and D. Xiao, J. Chromatogr. A, 2006, 1107(1-2), 290-293.

12 Z. Q. Zhang and Y. Tang, Anal. Bioanal. Chem., 2005, 381(4), 932-936.

13 S. M. Wabaidur, S. M. z Alam, S. H. Lee, Z. A. Alothman and G. E. Eldesoky, Spectrochim. Acta A, 2013, 105, 412-417. 
14 N. Paksoy, S. Kiliç Altun and H. Durmaz, S. Afr. J. Anim. Sci., 2018, 48(6), 1110-1114.

15 S. H. Zhao, P. P. Zhang, X. H. Liang, D. L. Hua, T. S. Ma and G. L. Pei, J. Food Sci., 2012, 77(1), C102-C106.

16 A. Pathak and S. J. Rajput, Indian J. Pharm. Sci., 2008, 70, 513. 17 M. V. de Moura Ribeiro, I. da Silva Melo, F. das Chagas da Costa Lopes and G. C. Moita, Braz. J. Pharm. Sci., 2016, 52(4), 741-750.

18 R. Gürkan and N. Altunay, Food Addit. Contam. A, 2016, 33(7), 1127-1138.

19 F. J. Aberásturi, A. I. Jiménez, J. J. Arias and F. Jiménez, Anal. Lett., 2002, 35(10), 1677-1691.

20 F. J. Lara, A. M. García-Campaña and A. I. Velasco, Electrophoresis, 2010, 31(12), 1998-2027.

21 S. S. Zhao, X. Zhong, C. Tie and D. D. Chen, Proteomics, 2012, 12(19-20), 2991-3012.

22 V. Poinsot, V. Ong-Meang, P. Gavard and F. Couderc, Electrophoresis, 2014, 35(1), 50-68.
23 S. X. Yang, S. Y. Ma, K. L. Zhu, M. L. Wang, J. H. Li, M. Arabi, H. T. Liu, Y. Li and L. X. Chen, J. Food Compos. Anal., 2020, 88, 103462.

24 H. Shi, X. Xu, Y. Ding, S. Liu, L. Li and W. Kang, Anal. Biochem., 2009, 387(2), 178-183.

25 X. Xu, H. Zhang, H. Shi, C. Ma, B. Cong and W. Kang, Anal. Biochem., 2012, 427(1), 10-17.

26 S. Y. Liao and C. W. Whang, J. Chromatogr. A, 1996, 736(1-2), 247-254.

27 Y. Hu, X. Li and Z. Pang, J. Chromatogr. A, 2005, 1091(1-2), 194-198.

28 X. D. Xu, Y. G. Hu and Z. Y. Yang, Chin. Chem. Lett., 2006, 17(7), 925-928.

29 L. Zhang, Y. Zhao, J. Huang and S. Zhao, J. Chromatogr. B, 2014, 967, 190-194.

30 M. A. Raggi, C. Sabbioni, G. Casamenti, G. Gerra, N. Calonghi and L. Masotti, J. Chromatogr. B, 1999, 730(2), 201-211.

31 A. Blikungeri, M. Pelletier and D. Monnier, Inorg. Chim. Acta, 1977, 22, 7-14. 